\title{
STRESS MODIFIED CRITICAL STRAIN CRITERION FOR S235JR STEEL AT LOW INITIAL STRESS TRIAXIALITY
}

\author{
Pawe€ Grzegorz Kossakowski \\ Kielce University of Technology, Faculty of Civil Engineering and Architecture, Kielce, Poland \\ e-mail:kossak@tu.kielce.pl
}

\begin{abstract}
Ductile fracture of low carbon structural steel (S235JR) at low initial stress triaxiality has been predicted using a method based on the Stress Modified Critical Strain (SMCS) criterion and the Gurson-Tvergaard-Needleman (GTN) material model. The influence of microdefects on the material strength has been taken into account. The investigations, including tensile tests, have been conducted for standard cylindrical unnotched tensile specimens at low triaxial stresses. An advanced finite element method has been used to determine several SMCS model parameters.

Keywords: Stress Modified Critical Strain (SMCS) criterion, Gurson-Tvergaard-Needleman (GTN) material model, numerical simulations, S235JR steel
\end{abstract}

\section{Introduction}

Assessment of the load-carrying capacity of structural elements that are damaged or overloaded is a common problem encountered in engineering practice. In either case, if the capacity of elements is exceeded, the structure, especially when made of steel, is no longer safe. In extreme cases, the structure may operate in a pre-failure state, leading finally to a catastrophe. The load-carrying capacity analysis becomes more complicated when structural elements are plastically deformed or otherwise damaged. Risk assessment is absolutely necessary for structures showing signs of failure, i.e., visible deformations or cracks.

A thorough analysis of the load-carrying capacity of structural elements made of steel in a pre-failure condition is definitely difficult, mainly because of the high complexity of the problem. Some structural elements are able to operate without failure even though they are beyond the elastic limit. In such a case, we cannot apply methods based on the classic strength hypotheses; we can only use assumptions and methods of the theory of plasticity.

Serious engineering problems may also be attributable to cracks. Cracks affect the load-carrying capacity of single elements, and consequently, the entire structure. It can be difficult to assess stresses around a crack and determine their influence on the load-carrying capacity of an element and on the real fracture toughness of the material, i.e., steel. The knowledge of the type of fracture is crucial. When brittle or plastic fracture occurs, we can use the classic methods of fracture mechanics. In the case of transition or elastic-plastic fracture, however, we may find it highly problematic to correctly assess the fracture toughness. Other important problems that should be analyzed by structural engineers are the influence of defects of structural elements on the stability of whole structures as well as the influence of defects of welds on the load-carrying capacity of welded connections.

Even though many procedures have been developed and fracture mechanics provides some well-defined criteria, the analysis of the load-carrying capacity of an element containing a crack is likely to be affected by various parameters, the choice of which is no longer obvious. It is essential to consider the criteria for the application of linear and nonlinear fracture mechanics. They are dependent on the size and shape of the plastic zone, which can be measured using many 
acceptable methods. In the case of full plasticity, accurate assessment of the fracture toughness can be difficult because of the problems with measurement of the critical value of the J-integral. Other material constants can also be used for the analysis in a fairly wide range (minimum, mean or probable values), and they may significantly affect the results. Hence the need to systematize and unify the methodology for assessing the strength and safety of mechanical systems and building structures.

Many components used in construction are made of steel. Crack initiation in steel is related to the material microstructure, thus, ductile fracture is a basic mechanism of the failure. Micro-cracks occur as a result of micro-defects (voids) present in the material structure nucleating on inclusions and second-phase particles in the material matrix. The nucleation, growth and coalescence of voids are the consecutive steps in the micro-damage evolution. The void growth is responsible for the development of localized plastic deformations, being the most important stage leading to material failure.

Ductile fracture has been analyzed by many researchers, but many problems are still necessary to solve. For instance, experimental methods are used to analyze the coalescence of voids. To find out more about ductile fracture, we need to carry out more extensive research and develop more effective methods for determining the load-carrying capacity and predicting the failure time.

Today, one of the methods used for predicting ductile fracture as a function of multi-axial stresses and strains in the plastic range is the Stress Modified Critical Strain (SMCS) model. The model seems to be a very useful method from the practical point of view in comparison with the conventional fracture toughness methods. To determine the ductility of a material, the SMCS model uses quantitative results, whereas in a traditional Charpy impact test, for example, assessment is made on the basis of qualitative data. The SMCS model may be used also in analyses of structural elements with no visible cracks, when there is no crack tip yielding. Engineers applying this model deal with multi-axial, especially triaxial, stresses, and strains in the plastic range. In traditional methods, analysis is based on the maximum plastic strains.

The SMCS method combines experimental testing with numerical analysis, with the latter being particularly important here. Selecting the best model to assess the failure of a given metal material is the most significant decision that a structural engineer needs to make.

Phenomena connected with ductile fracture may be analyzed and simulated using damage material models, taking into account the influence of microstrucural defects on the material strength. One of the first damage material models to take into consideration the relationship between the particular stages of failure and the strength of material was the Gurson material model (1977) developed for porous media. In the Gurson yield function, being a modified form of the Huber-Mises-Hencky hypothesis, the strength of a material is affected by an increase in the void volume fraction. The original Gurson model has undergone various modifications. The main ones were proposed by Tvergaard (1981), Tvergaard and Needleman (1984), and Needleman and Tvergaard (1984). The resulting Gurson-Tvergaard-Needleman (GTN) material model is now one of the basic damage models recommended for use in analysis of ductile fracture. The GTN material model may be helpful in modelling and simulating the stresses and strains during material failure, as they are parameters that are necessary to determine the failure criteria based on the other models, such as the SMCS model.

In this study, ductile fracture in structural steel was predicted by means of a method that is a combination of the SMCS and GTN models. The mechanisms of ductile crack initiation were modelled using the spatial distributions of stresses and strains at the microscale. Although this approach focuses on fracture behaviour, which is a particularly complex issue, the model is anticipated to become a useful tool for solving various engineering problems. It is important that ductile fracture should be analyzed by referring to the microstructural aspects and that failure in the particular steel elements should be predicted on the basis of quantitative data. 
Much of the previous research on the SMCS method has focused on mechanical engineering applications and on steels that are not common in construction. This study has been conducted for low-carbon S235JR steel, which is a basic steel used in the construction industry in Poland and other European countries. S235JR steel is applied to produce a number of structural elements, especially for construction applications. To predict and prevent failures and collapses of steel structures in construction, engineers need reliable methods for predicting failure processes in the material and the element under load conditions. It is thus vital to develop failure criteria for structural steels used in construction, including S235JR steel.

This paper analyzes the applicability of the SMCS model to engineering problems with regard to S235JR steel. The study has been conducted for cylindrical unnotched specimens at low initial stress triaxiality $\sigma_{m} / \sigma_{e}=1 / 3$, where $\sigma_{m}$ and $\sigma_{e}$ denote the hydrostatic stress and the effective stress, respectively. The investigations have been partially based on the results presented by Kossakowski (2012a,b). They involved performing a microstructural analysis, tensile tests and an advanced finite element analysis by means of the GTN model. The fundamental purpose of the study, however, is to determine the SMCS criterion at low initial stress triaxiality for S235JR steel.

\section{The SMCS model and the length scale parameter}

The SMCS model is one of the methods used for the assessment of material failure based on the relationship between the spatial plastic strain and the stress state at failure. The fundamental assumptions of the SMCS model were prepared by McClintock (1968) and Rice and Tracey (1969), who focused on the void growth phenomenon leading to the material failure. They noticed that the void growth is due to changes in the strain and stress state, defined by two key parameters, the effective strain $\varepsilon_{e}^{p l}$ and the stress triaxiality $\sigma_{m} / \sigma_{e}$. The SMCS model and method were further improved by Hancock and Mackenzie (1976), Hancock and Brown (1983), Johnson and Cook (1985), Marino et al. (1985), Panontin and Sheppard (1995), Bandstra et al. (2004), Benzerga et al. (2004), Kanvinde and Deierlein (2004, 2006) and Chi et al. (2006).

As mentioned before, ductile fracture is a complex phenomenon, dependent on many factors such as anisotropy of the void distribution, spacing and shape, void nucleation, changes and evolution in void shapes, void-to-void interactions, primary void nucleation and the nucleation and growth of secondary voids. As the models of these phenomena are too complex and advanced to use in common engineering practice, it is necessary to propose a simple and accurate method to simulate ductile fracture to use in engineering assessments.

Assuming that ductile fracture is largely dependent on void growth, and that void nucleation does not affect the ductile fracture process significantly, the void coalescence may be modelled and defined by the critical void ratio only, neglecting the void-to-void interactions or void localization. The void growth phenomenon has been analyzed by many researchers, including Berg (1962), Rice and Tracey (1969), McClintock (1968), Thomason (1968), and Brown and Embury (1973).

According to the SMCS model applied in this study, prediction of ductile failure requires considering the relationship between stress triaxiality and plastic strain only. From these assumptions, it is clear that we can apply the SMCS failure criterion to low carbon steels, commonly used in the construction industry. Ductile crack initiation in these steels is mainly due to the growth and coalescence of voids responsible for the development of localized plastic deformations.

The SMCS fracture criterion enables us to evaluate the initiation of ductile fracture depending on the stress and strain, defined by multi-axial stresses and plastic strains. The relationship between instantaneous stresses and strains at fracture initiation can be used to determine the critical plastic strain $\varepsilon_{c}^{p l}$, being a critical parameter, as a function of stress triaxiality $\sigma_{m} / \sigma_{e}$. 
According to the SMCS model, the critical plastic strain $\varepsilon_{c}^{p l}$ is calculated as

$$
\varepsilon_{c}^{p l}=\alpha \exp \left(-\frac{3}{2} \frac{\sigma_{m}}{\sigma_{e}}\right)
$$

where $\alpha$ is the toughness parameter, $\sigma_{m}$-hydrostatic stress, $\sigma_{e}$-effective stress.

The toughness parameter $\alpha$ is a constant for the material tested, generally determined through experiments. This parameter is established by combining the experimental and numerical methods. The time to failure is calculated from the results of the strength test, while the critical plastic strain $\varepsilon_{c}^{p l}$ is obtained through numerical simulations of the stress and strain state at failure. The toughness parameter $\alpha$ can be calculated as follows

$$
\alpha=\frac{\varepsilon_{c}^{p l}}{\exp \left(-\frac{3}{2} \frac{\sigma_{m}}{\sigma_{e}}\right)}
$$

During the numerical simulations performed by means of the material damage models, several problems have been encountered. When ductile fracture was simulated with a finite element method, i.e., in the nonlinear range, the mesh-size effects revealed the softening of the final part of the strength curve. This phenomenon is strictly connected with the fracture processes occurring at the micro-scale.

According to the fracture criterion, two conditions must be satisfied to initiate a crack. The critical stress and the plastic strain must be exceeded over the critical volume of the material, which, in a two-dimensional analysis, is defined by the characteristic length $l_{c}$. Thus, the SMCS fracture criterion can be written as

$$
\varepsilon^{p l}>\varepsilon_{c}^{p l} \quad \text { over } \quad r>l_{c}
$$

where $\varepsilon^{p l}$ is the plastic strain, $\varepsilon_{c}^{p l}$ - critical plastic strain, $r$ - length, $l_{c}$ - characteristic length.

Fracture condition (2.3) is shown schematically in Fig. 1, where the region of high stress and plastic strain is presented. The fundamental parameter is the difference between the effective strain $\varepsilon_{e}^{p l}$ and the critical plastic strain $\varepsilon_{c}^{p l}$, marked by contours to indicate the subsequent loading steps in the region near the crack tip.

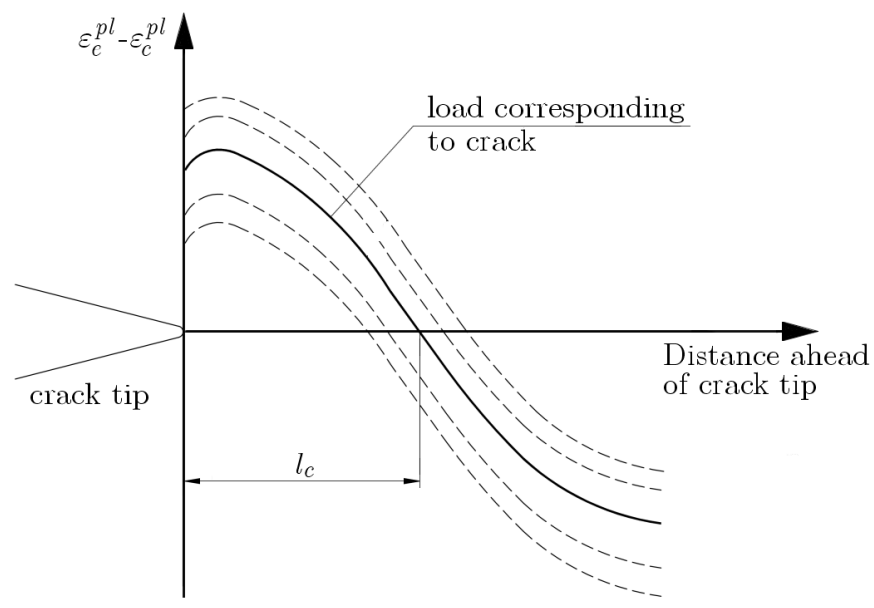

Fig. 1. Predicting ductile crack initiation defined by the characteristic length $l_{c}$ (based on Kanvinde and Deierlein, 2006)

Crack formation is predicted for a progressively increasing distance until the fracture criterion is satisfied over the characteristic length $l_{c}$. The first loading step when the fracture criterion is satisfied over the characteristic length $l_{c}$ corresponding to fracture initiation is presented as a solid line. 
As can be seen, the characteristic length $l_{c}$ is a basic parameter determining the crack initiation process, which is particularly important in numerical simulations of ductile fracture. The characteristic length $l_{c}$ defines the proper mesh size in the region prone to crack initiation and, accordingly, failure. The parameter is vital in the modelling of regions with high stress-strain gradients, for instance, the area near the crack tip. The SMCS fracture criterion is satisfied when the size of the finite elements is exceeded over the critical volume of the material, represented in two dimensions by the characteristic length $l_{c}$. Summing up, the mesh size should be at least equal to the characteristic length $l_{c}$. The theory and methods used to determine the characteristic length $l_{c}$ are presented further in the paper.

\section{The GTN material model}

As mentioned before, the Gurson material model for porous media is one of the material damage models that take into account the influence of microstrucural defects on the material strength. The Gurson yield criterion replaced the Huber-Mises-Hencky yield criterion. It is assumed that the proportion of voids in the plastic potential function is dependent on the void volume fraction $f$, defining the influence of microfailure (pores, voids) on the material strength.

According to the GTN model, failure loads related to ductile fracture can be determined by analyzing some microstructural parameters and plastic properties of the material. As shown in many studies conducted for alloys and structural steels, the GTN model provides good agreement between the predictions and the experimental data. To numerically model the load limit for any element subjected to any load, we need to apply an appropriate procedure and take the effects of micro-failure into account. The parameters of the material microstructure can be determined by analyzing the actual data rather than matching the parameters to the tensile test results. Accordingly, the load-carrying capacity can be calculated numerically by analyzing the stress state, changes in the microstructure and, finally, the safety reserves of the particular elements.

The GTN yield criterion modified by Tvergaard (1981), Tvergaard and Needleman (1984) and Needleman and Tvergaard (1984) is written as

$$
\Phi=\left(\frac{\sigma_{e}}{\sigma_{0}}\right)^{2}+2 q_{1} f^{*} \cosh \left(-q_{2} \frac{3 \sigma_{m}}{2 \sigma_{0}}\right)-\left(1+q_{3} f^{* 2}\right)=0
$$

where $\sigma_{e}$ is the effective stress, $\sigma_{0}$-yield stress, $\sigma_{m}$ - hydrostatic stress, $f^{*}$ - modified void volume fraction, $q_{i}$ - Tvergaard's parameters.

As can be seen, the material porosity is dependent on the modified void volume fraction $f^{*}$

$$
f^{*}= \begin{cases}f & \text { for } \quad f \leqslant f_{c} \\ f_{c}+\frac{\bar{f}_{F}-f_{c}}{f_{F}-f_{c}}\left(f-f_{c}\right) & \text { for } \quad f_{c}<f<f_{F} \\ \bar{f}_{F} & \text { for } f \geqslant f_{F}\end{cases}
$$

where $f_{c}$ is the critical void volume fraction, $f_{F}$ - void volume fraction at final fracture

$$
\bar{f}_{F}=\frac{q_{1}+\sqrt{q_{1}^{2}-q_{3}}}{q_{3}}
$$

An increase in the void volume fraction $\dot{f}$ is defined by the following relationship

$$
\dot{f}=\dot{f}_{g r}+\dot{f}_{n u c l}=(1-f) \dot{\varepsilon}^{p l}: \mathbf{I}+\frac{f_{N}}{s_{N} \sqrt{2 \pi}} \exp \left[-\frac{1}{2}\left(\frac{\varepsilon_{e m}^{p l}-\varepsilon_{N}}{s_{N}}\right)^{2}\right] \dot{\varepsilon}_{e m}^{p l}
$$


where $\dot{f}_{g r}$ denotes the void growth rate, $\dot{f}_{\text {nucl }}$ - void nucleation rate, $f_{N}$ - volume fraction of void nucleating particles, $s_{N}$ - standard deviation of nucleation strain, $\dot{\varepsilon}^{p l}$ - plastic strain rate tensor, $\mathbf{I}$ - second-order unit tensor, $\varepsilon_{N}$ - mean strain for void nucleation, $\varepsilon_{e m}^{p l}$ - effective strain, $\dot{\varepsilon}_{e m}^{p l}$ - effective strain rate.

The GTN material model is an advanced material damage model with many parameters. Nevertheless, it is commonly used in various areas of engineering to simulate the load-carrying capacity and failure of structures. The GTN material model is recommended for use by some European standards (e.g. PN-EN 1993-1-10 (2007)) and related publications (Sedlacek et al., 2008) to analyze pre-failure behaviour of buildings and other structures.

In this study, the GTN model has been used for determining the distributions of strains and stress triaxility necessary to obtain the SMCS criterion for S235JR steel.

\section{The SMCS criterion for S235JR steel at low initial stress triaxiality}

This analysis has been conducted for elements made of S235JR steel under triaxial stresses. The SMCS criterion is defined in subsequent steps. The investigations include a microstructural analysis, tensile tests, and numerical simulations.

\subsection{The microstructural analysis}

S235JR is a general purpose non-alloy structural steel used for welded, load-carrying, and dynamically loaded structures. It is a lower grade steel with large amounts of impurities. The maximum content of elements in [\%] is: $\mathrm{C}=0.14, \mathrm{Mn}=0.54, \mathrm{Si}=0.17, \mathrm{P}=0.016, \mathrm{~S}=0.026$, $\mathrm{Cu}=0.29, \mathrm{Cr}=0.12, \mathrm{Ni}=0.12, \mathrm{Mo}=0.03, \mathrm{~V}=0.002$ and $\mathrm{N}=0.01$. The basic microstructural parameters of S235JR steel determined through experimental testing are porosity and characteristic length. The steel has a ferritic-perlitic structure with a large number of non-metallic inclusions. The initial porosity has been determined on the basis of the initial void volume fraction, $f_{0}=0.0017=0.17 \%$ (Kossakowski, 2010).

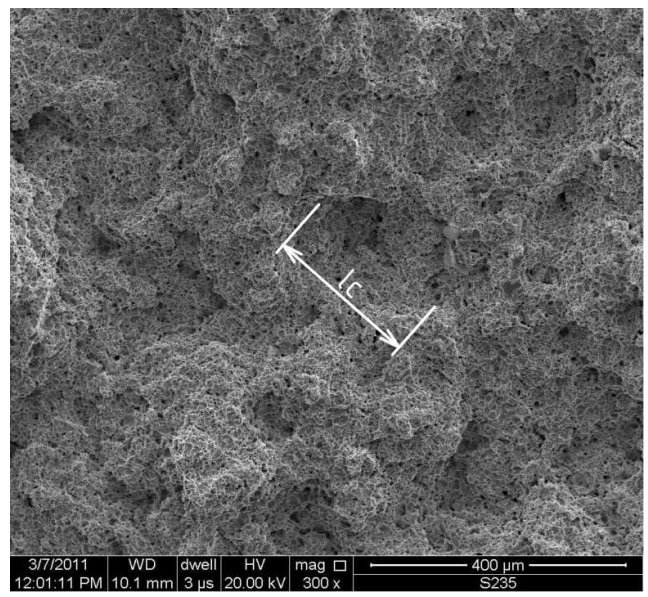

Fig. 2. Fracture areas with the characteristic length $l_{c}$

The characteristic length $l_{c}$ in the fracture area after standard tensile tests has been established using the microstructural images. It is important to note that the determination of the characteristic length is subjective. The methods used for this purpose include those discussed by Panontin and Sheppard (1995), Chi et al. (2006) and Rousselier (1987). In this study, the Hancock and Mackenzie (1976) method has been applied. The fractograph in Fig. 2 shows fracture initiation being a result of the coalescence of two or more voids forming from inclusion colonies. The characteristic length $l_{c}$ has been determined as the length of a dimple formed as a result of void coalescence. On average, the characteristic length was $l_{c} \approx 250 \mu \mathrm{m}$ (Kossakowski, 2012a). 


\subsection{The GTN material model parameters for S235JR steel}

Experimental and numerical methods have been combined to determine the GTN material model parameters for S235JR steel, as described by Kossakowski (2010, 2012a,b). First, standard tensile tests have been performed according to PN-EN 10002-1 (2004) using specimens with a circular cross-section (the nominal diameter, $d=10 \mathrm{~mm}$, the initial length, $l_{0}=50 \mathrm{~mm}$, and the initial cross-sectional area, $S_{0}=78.5 \mathrm{~mm}^{2}$ ). The testing has been conducted with a 322 MTS testing machine, which has a capacity of $100 \mathrm{kN}$ and is equipped with a hydraulic drive able to control an increase in displacements. The measurements involved registering values of load and strain in the central part of the specimens using an extesometer with a gauge length of $35 \mathrm{~mm}$. The sample size is $n=8$ specimens. The strength properties obtained for S235JR steel for the significance level of 0.05 are as follows: the yield stress $R_{0.2}=318.3 \pm 2.59 \mathrm{MPa}$ with standard deviation $s=3.73 \mathrm{MPa}$, the tensile strength $R_{m}=457.4 \pm 4.91 \mathrm{MPa}$ with standard deviation $s=7.09 \mathrm{MPa}$, and the percentage elongation $A_{t}=33.9 \pm 1.47 \%$ with standard deviation $s=2.13 \%$ (Kossakowski, 2012a,b). The modulus of elasticity is $E=205 \mathrm{GPa}$.

The values of the normal stress $\sigma$ and the longitudinal strain $\varepsilon$ have been used to develop the elastic-plastic material model for S235JRS steel, as reported by Kossakowski (2012a). Taking into consideration the full response of S235JR steel in the plastic range (visible material softening and hardening), Kossakowski (2012a) wrote the approximation function $\sigma(\varepsilon)$ as

$$
\varepsilon=\left\{\begin{array}{lll}
\frac{\sigma}{E} & \text { for } \quad \sigma<\sigma_{0} \\
\frac{\varepsilon_{1}-\varepsilon_{0}}{\sigma_{1}-\sigma_{0}}\left(\sigma-\sigma_{0}\right)+\varepsilon_{0} & \text { for } \quad \sigma_{0} \leqslant \sigma \leqslant \sigma_{1} \\
\varepsilon_{0}+\frac{\sigma_{01}}{E}\left(\frac{\sigma}{\sigma_{01}}\right)^{1 / N} & \text { for } \quad \sigma>\sigma_{1}
\end{array}\right.
$$

where $\varepsilon$ is the strain, $\varepsilon_{0}$-yield strain, $\varepsilon_{1}$ - initial hardening strain, $\sigma$-stress, $\sigma_{0}$-yield stress, $\sigma_{1}$ - initial hardening stress, $\sigma_{01}$ - initial stress at the beginning of the nonlinear part of the approximation curve, $E$ - modulus of elasticity, $N$ - strain-hardening exponent.

The strength response of S235JR steel described by model (4.1) has been used to determine the GTN model parameters. First, the fundamental GTN parameter, initial porosity defined by the void volume fraction, has been determined through microstructural analysis as $f_{0}=0.0017$.

Like in the work by Faleskog et al. (1998), Tvergaard's parameters have been established on the basis of the strength properties obtained experimentally. The values of Tvergaard's parameters are: $q_{1}=1.91, q_{2}=0.79$ and $q_{3}=3.65$ for $R_{0.2} / E=0.00155$ and the strain-hardening exponent $N=0.195$.

The other parameters of the GTN model have been determined by combining the experimental and numerical methods, as described by Kossakowski (2010, 2012a,b). The results of the tensile tests have been modelled numerically using a program based on the Finite Element Method, Abaqus Explicit version 6.10. The GTN material model parameters have been established numerically on the basis of the $\sigma(\varepsilon)$ curves obtained experimentally. The values of the GTN parameters have been changed iteratively within certain limits using the optimization criterion based on the convergence of the $\sigma(\varepsilon)$ strength curves obtained numerically and experimentally. All the GTN material model parameters for S235JR steel are summarized in Table 1.

Table 1. Microstructural parameters of the GTN model for S235JR steel (Kossakowski, 2012a)

\begin{tabular}{|c|c|c|c|c|c|c|c|c|}
\hline$f_{0}$ & $f_{c}$ & $f_{F}$ & $q_{1}$ & $q_{2}$ & $q_{3}$ & $\varepsilon_{N}$ & $f_{N}$ & $s_{N}$ \\
\hline \hline 0.0017 & 0.06 & 0.667 & 1.91 & 0.79 & 3.65 & 0.3 & 0.04 & 0.05 \\
\hline
\end{tabular}




\subsection{The SMCS criterion for S235JR steel at low initial stress traxiality}

The analysis of the SMCS criterion for S235JR steel at low initial stress triaxiality has been determined using the results of the tensile tests obtained for unnotched specimens with a circular cross-section. The minimum initial stress triaxiality $\sigma_{m} / \sigma_{e}$ is $1 / 3$. The key parameters of the SMCS model, i.e., the critical strain and stress triaxiality, have been determined by using the strength curves obtained during experiments with the spatial stress-strain distributions at failure modelled numerically by means of the GTN material model.

The force-elongation $F(l)$ curves obtained experimentally and numerically are shown in Fig. 3. The time to failure is the fundamental parameter required to establish the spatial stress-strain distributions.

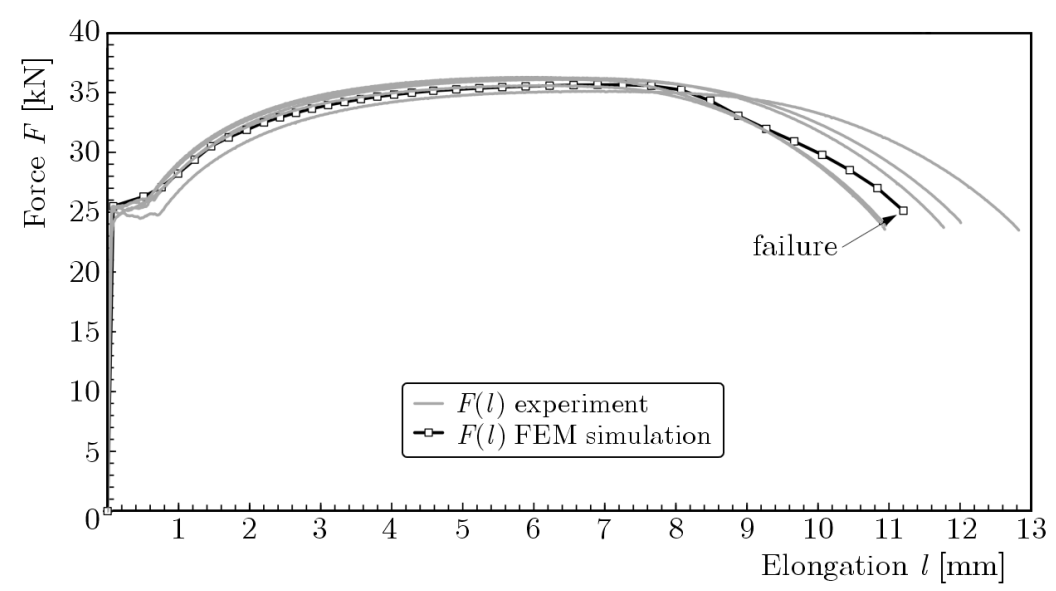

Fig. 3. Force-elongation $F(l)$ curves obtained during the experiments and numerical simulations for S235JR steel at low initial stress triaxiality

The stress-strain state has been determined by numerically simulating the tensile test results using the Abaqus Explicit version 6.10, a program based on the Finite Element Method. The main idea is to couple the SMCS and GTN models to predict fracture in the structural steel on the basis of the failure criterion (2.3). The distributions of stress and strain at material failure have been identified numerically using the GTN material model, which enabled us to determine the SMCS failure criterion for S235JR steel at low initial stress triaxiality.

In the numerical simulations, axially symmetrical elements, representing specimens with a circular cross-section, have been subjected to static tension with strain increasing at a rate of $10^{-2} \mathrm{~s}^{-1}$. The modelling has been performed on $1 / 4$ specimens because of the specimen symmetry. For this approach, it is possible to block horizontal displacements along the specimen axis (left edge of the model) and vertical displacements in the crack tip region (lower edge of the model), as shown in Fig. 4.

Crack formation is initiated by producing a sharp notch $(R=0.05 \mathrm{~mm})$ at the bottom of the numerical model, in the middle of the gauge length. The process zone has been modelled using microstructural length scales suitable for S235JR steel. The dimensions of the finite elements localized near the crack plane are $D \times D / 2$, where $D$ corresponds to the characteristic length $l_{c}=250 \mu \mathrm{m}$ (Fig. 4). There are 120 finite elements in the failure zone and 484 finite elements in the other regions. The number of nodes was 670 . The GTN material model developed for porous media has been adapted to suit the whole numerical model using the parameters provided in Table 1.

The effect of the FEM mesh density has been analyzed for an approach in which the size of the FEM mesh corresponds to the distance between primary voids in the material structure. The FEM model has been constructed in the same way as the fundamental FEM model based on the $250 \times 250 \mu \mathrm{m}$ mesh in the fracture zone. In the model analyzed here, the size of the 


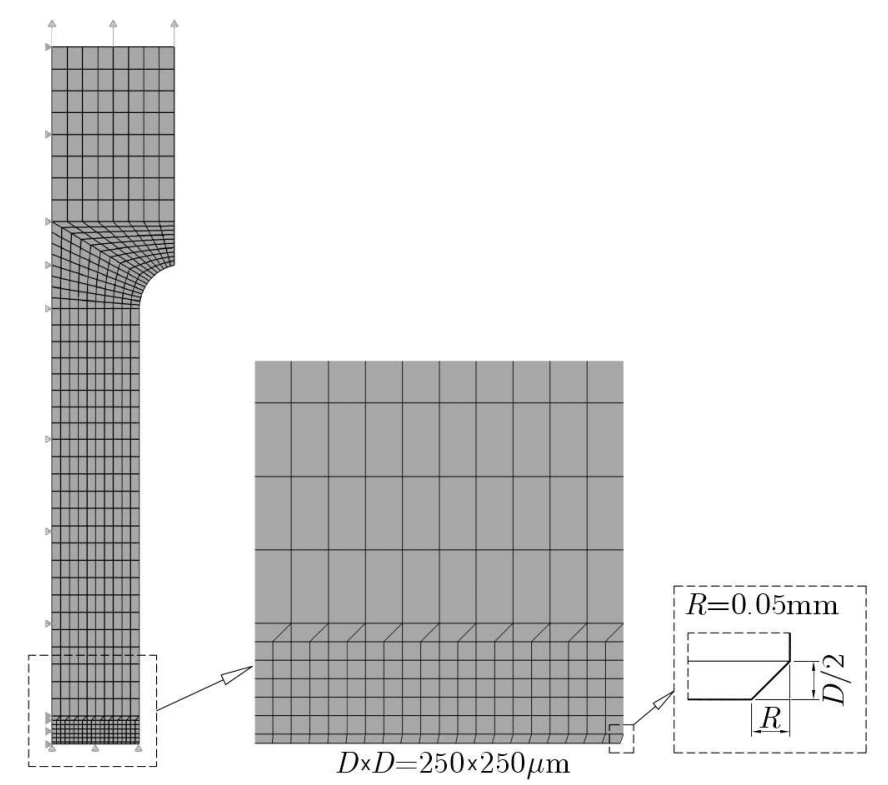

Fig. 4. Geometry of the numerical models used for the simulations

FEM mesh has been established on the basis of the average distance between primary voids, which is $100 \mu \mathrm{m}$ (Kossakowski, 2012a). The size of the mesh in the failure zone is $100 \times 100 \mu \mathrm{m}$. The values of and the relationships between the stress triaxiality ratio $\sigma_{m} / \sigma_{e}$ and the effective strain $\varepsilon_{e}^{p l}$ in the failure plane are almost identical as those observed in the fundamental model based on a $250 \mu \mathrm{m}$ mesh. It is important to note that there is no considerable difference between the toughness parameter $\alpha$ for an FEM mesh with a greater density and that obtained for a $250 \times 250 \mu \mathrm{m}$ mesh in the failure zone, because it is only $2.7 \%$ lower. It can be concluded that the density of the FEM mesh with finite elements ranging $100-250 \mu \mathrm{m}$ in the failure zone has no significant effect. Taking account of this and good convergence of the results of tensile test simulations with a mesh based on the length scale $l_{c}$, i.e. a $250 \times 250 \mu \mathrm{m}$ mesh in the failure zone, we assume that this mesh size is fundamental. The results presented below concern the approach with the $250 \times 250 \mu \mathrm{m}$ FEM mesh density in the failure zone.

Failure has been identified numerically on the basis of the force-elongation curves shown in Fig. 3, taking into consideration the time to failure observed during the experiments. The corresponding stress-strain state has been determined using the GTN material model, i.e., by analyzing the influence of the micro-defects on the material strength. Figure 5 shows the distributions of the effective strain $\varepsilon_{e}^{p l}$ and the stress triaxiality $\sigma_{m} / \sigma_{e}$ determined at a load corresponding to that at the fracture initiation.

As can be seen from Fig. 5, the most intensive distributions of the effective strain $\varepsilon_{e}^{p l}$ and the stress triaxiality $\sigma_{m} / \sigma_{e}$ at failure are observed in the central part of the elements, along the axis of symmetry. This region is the most prone to crack initiation. Therefore, the critical stress-strain distributions in this region have been used to determine the SMCS failure criterion for S235JR steel. The critical SMCS parameters have been based on the stress triaxiality $\sigma_{m} / \sigma_{e}$ and effective strain $\varepsilon_{e}^{p l}$ curves determined at fracture initiation at the nodes of the finite elements along the line from the centre of the cross-section of the fracture region up to the side, as shown in Fig. 6.

It can be seen that the stress triaxiality changes significantly along the line going from the centre of the minimum cross-section to the side. At the central point, $\sigma_{m} / \sigma_{e}=1.123$, while at the end $\sigma_{m} / \sigma_{e}=0.318$. The effective strain distribution is similar, but the differences at the central and end points are smaller. At the central point, the effective strain $\varepsilon_{e}^{p l}$ was 0.997 , while at the end $\varepsilon_{e}^{p l}$ was 0.760 . 
(a)

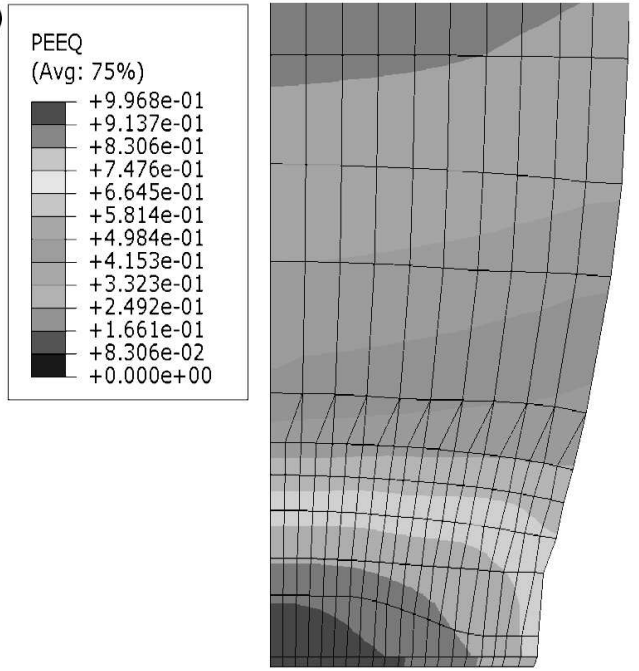

(b)

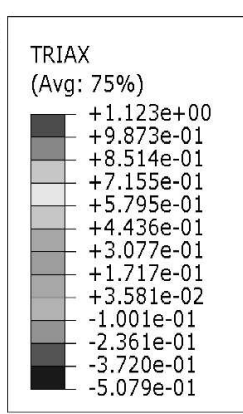

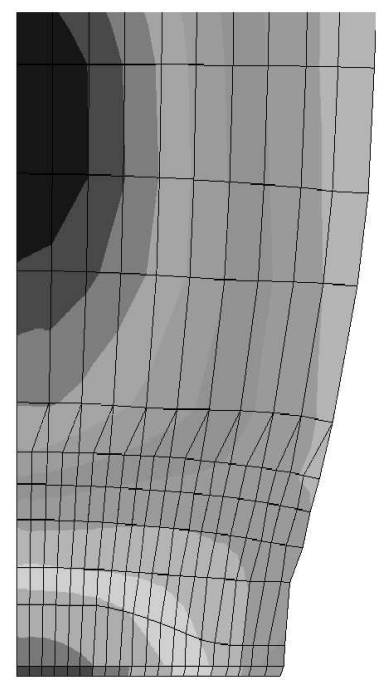

Fig. 5. Distributions of the effective strain $\varepsilon_{e}^{p l}(\mathrm{a})$ and the stress triaxiality $\sigma_{m} / \sigma_{e}$ (b) at failure

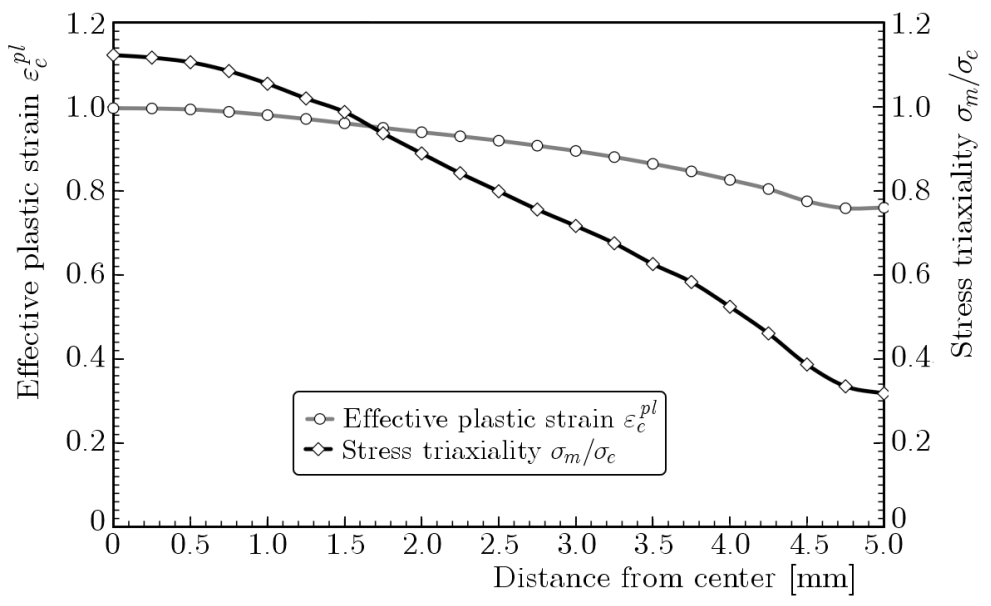

Fig. 6. Stress triaxiality $\sigma_{m} / \sigma_{e}$ and the effective strain $\varepsilon_{e}^{p l}$ curves

The distributions and the critical values in the region prone to crack initiation and failure have been determined as the critical plastic strain, $\varepsilon_{c}^{p l}=0.997$, and the corresponding stress triaxiality, $\sigma_{m} / \sigma_{e}=1.123$. According to formula (2.2), the toughness parameter $\alpha$ has been calculated as

$$
\alpha=\frac{\varepsilon_{c}^{p l}}{\exp \left(-\frac{3}{2} \frac{\sigma_{m}}{\sigma_{e}}\right)}=5.374
$$

The value of the toughness parameter, $\alpha=5.374$, may be treated as the material constant for S235JR steel at low initial stress triaxiality, $\sigma_{m} / \sigma_{e}=1 / 3$, in the static range. The method and the criterion presented above can be applied to solve practical engineering problems. According to the SMCS criterion, the failure of S235JR steel can be predicted using the following condition

$$
\varepsilon^{p l}>\varepsilon_{c}^{p l}=5.374 \exp \left(-\frac{3}{2} \frac{\sigma_{m}}{\sigma_{e}}\right)
$$

It should be noted that the SMCS criterion, (4.3), may be applied also to steel grades with metallurgical content and strength properties comparable with those of S235JR steel in the case of low initial stress triaxiality. 


\section{Conclusions}

The SMCS model applied to predict ductile fracture in steels seems superior to both the conventional fracture toughness methods and the more sophisticated assessment techniques. The SMCS model, based on the distributions of multi-axial, especially triaxial, stresses and plastic strains can also be used to analyze the behaviour of structural elements with no visible cracks, or no crack tip yielding. The model and the failure criterion seem well-suited for a wide range of engineering problems, especially the prediction of failure and the assessment of the load-carrying capacity of structures.

The conclusions can be summarized as follows:

- The SMCS criterion is an easy and universal tool to deal with various engineering problems related to the strength and load-carrying capacity of steel structural elements. It can be used to predict ductile crack initiation when cracks are not visible, when there is no crack tip yielding, in the case of large-scale yielding and in flaw-free geometries.

- By combining the SMCS criterion with the GTN model, we can determine the stress-strain state at failure. When the strength of a material is analyzed, the influence of micro-defects needs to be taken into account.

- The toughness parameter for S235JR steel is: $\alpha=5.374$. This value can be treated as the material constant to be used in the fracture condition when the material is under static triaxial stress. The SMCS criterion is defined as $\varepsilon^{p l}>\varepsilon_{c}^{p l}=5.374 \exp \left[-3 \sigma_{m} /\left(2 \sigma_{e}\right)\right]$.

- This failure criterion can be used for steel grades with metallurgical content and strength properties comparable with those of S235JR steel when under triaxial stress. The results can be used to solve a variety of engineering problems related to the load-carrying capacity and safety of structural elements made of steel grades typically used in the construction industry in Poland and other EU countries.

\section{References}

1. ABAQUS 6.10 Analysis User's Manual, 2010, Dassault Systèmes Simulia Corporation, Providence

2. Bandstra J.P., Koss D.A., Geltmacher A., Matic P., Everett R.K., 2004, Modeling void coalescence during ductile fracture of a steel, Materials Science and Engineering; A, 366, 2, 269-281

3. Benzerga A.A., Besson J., Pineau A., 2004, Anisotropic ductile fracture. Part II: Theory, Acta Materialia, 52, 15, 4639-4650

4. Berg C.A., 1962, The motion of cracks in plane viscous deformation, Proceedings of the Fourth U.S. National Congress of Applied Mechanics, University of California, Berkeley, June 18-21, edited by Rosenberg R.M., 2, 885-892

5. Brown L.M., Embury J.D., 1973, Initiation and growth of voids at second phase particles, Proceedings of the Third International Conference on the Strength of Metals and Alloys, Institute of Metals, London, 164-179

6. Chi W.-M., Kanvinde A.M., Deierlein G.G., 2006, Prediction of ductile fracture in steel connections using SMCS criterion, Journal of Structural Engineering, ASCE, 132, 2, 171-181

7. Faleskog J., Gao X., Shin C.F., 1998, Cell model for nonlinear fracture analysis - I. Micromechanics calibration, International Journal of Fracture, 89, 4, 355-373

8. Gurson A.L., 1977, Continuum theory of ductile rupture by void nucleation and growth: Part I - Yield criteria and flow rules for porous ductile media, Journal of Engineering Materials and Technology, Transactions of the ASME, 99, 1, 2-15

9. Hancock J.W., Mackenzie A.C., 1976, On the mechanisms of ductile failure in high-strength steels subjected to multi-axial stress-states, Journal of the Mechanics and Physics of Solids, 24, $2 / 3,147-160$ 
10. Hancock J.W., Brown D.K., 1983, On the role of strain and stress state in ductile failure, Journal of the Mechanics and Physics of Solids, 31, 1, 1-24

11. Johnson G.R., Cook W.H., 1985, Fracture characteristics of three metals subjected to various strains, strain rates, temperatures and pressures, Engineering Fracture Mechanics, 21, 1, 31-48

12. Kanvinde A.M., Deierlein G.G., 2004, Prediction of ductile fracture in steel moment connections during earthquakes using micromechanical fracture models, 13th World Conference on Earthquake Engineering, Vancouver, August 1-6, Paper No. 297

13. Kanvinde A.M., Deierlein G.G., 2006, The Void Growth Model and the Stress Modified Critical Strain Model to predict ductile fracture in structural steels, Journal of Structural Engineering, 132, $12,1907-1918$

14. Kossakowski P.G., 2010, An analysis of the load-carrying capacity of elements subjected to complex stress states with a focus on the microstructural failure, Archives of Civil and Mechanical Engineering, 10, 2, 15-39

15. Kossakowski P.G., 2012a, Simulation of ductile fracture of S235JR steel using computational cells with microstructurally-based length scales, Journal of Theoretical and Applied Mechanics, 50, $2,589-607$

16. Kossakowski P.G., 2012b, The numerical modeling of failure of S235JR steel using GursonTvergaard-Needleman material model, Roads and Bridges, 11, 4, 295-310

17. Marino B., Mudry F., Pineau A., 1985, Experimental study of cavity growth in ductile rupture, Engineering Fracture Mechanics, 22, 6, 989-996

18. MCClintock F.A., 1968, A criterion for ductile fracture by the growth of holes, Journal of Applied Mechanics, Transactions of the ASME, Series E, 35, 2, 363-371

19. Needleman A., TvergaArd V., 1984, An analysis of ductile rupture in notched bars, Journal of the Mechanics and Physics of Solids, 32, 6, 461-490

20. Panontin T.L., Sheppard S.D., 1995, The relationship between constraint and ductile fracture initiation as defined by micromechanical analyses, Fracture Mechanics: 26th Volume. ASTM STP, 1256, $54-85$

21. PN-EN 10002-1:2004 Metallic Materials - Tensile Testing - Part 1: Method of Test at Ambient Temperature

22. PN-EN 1993-1-10:2007 Eurocode 3 - Design of Steel Structures - Part 1-10: Material Toughness and Through-Thickness Properties

23. Rice J.R., Tracey D.M., 1969, On the ductile enlargement of voids in triaxial stress fields, Journal of the Mechanics and Physics of Solids, 17, 3, 201-217

24. Rousselier G., 1987, Ductile fracture models and their potential in local approach of fracture, Nuclear Engineering and Design, 105, 1, 97-111

25. Sedlacek G., Feldmann M., Kühn B., Tschickardt D., Höhler S., Müller C., Hensen W., Stranghöner N., Dahl W., Langenberg P., Münstermann S., Brozetti J., Raoul J., Pope R., BiJlaard F., 2008, Commentary and Worked Examples to EN 1993-1-10 "Material toughness and through thickness properties" and other toughness oriented rules in EN 1993, JRC Scientific and Technical Reports, Luxembourg: Office for Official Publications of the European Communities, http://eurocodes.jrc.ec.europa.eu/showpublication.php?id=134

26. Thomason P.F., 1968, A theory for ductile fracture by internal necking of cavities, Journal of the Institute of Metals, 96, 360-365

27. TVergaArd V., 1981, Influence of voids on shear band instabilities under plane strain conditions, International Journal of Fracture, 17, 4, 389-407

28. Tvergand V., Needleman A., 1984, Analysis of the cup-cone fracture in a round tensile bar, Acta Metallurgica, 32, 1, 157-169 